\title{
Compulsory schooling laws and the cure against child labor
}

\author{
Giorgio Bellettini and Carlotta Berti Ceroni* \\ Department of Economics \\ University of Bologna
}

November 16, 2000

\begin{abstract}
Equally poor countries display similar compulsory schooling laws but different levels of child labor and school attendance. This paper provides an explanation for the existence of child labor which relies on the imperfect enforcement of compulsory schooling laws and is consistent with the above cross-country differences. In the presence of complementarities in the production of human capital that justify legislative intervention, mandatory measures ensure that coordination failures are solved so that all parents send their children to school and the socially optimal equilibrium is reached. However, if enforcement of legislation is too low, multiple equilibria emerge. In this case, child labor occurs more often among poor households, and compulsory schooling laws may have adverse welfare effects.
\end{abstract}

JEL Classification Numbers: J13, J24, O11

${ }^{*}$ Bellettini: Dipartimento di Scienze Economiche, P.zza Scaravilli 2, 40126 Bologna Italy. Email: belletti@economia.unibo.it. Berti Ceroni: Dipartimento di Scienze Economiche, P.zza Scaravilli 2, 40126 Bologna Italy. Email: bceroni@economia.unibo.it. We would like to thank participants at the Asset 2000 conference in Lisbon. The usual disclaimer applies. 
"It would be high for the advantage of everybody, if everybody were to act in a certain matter, but in which it is not the interest of any individual to adopt the rule for the guidance of his own conduct, unless he has some security that others will do so too. [w]ho is to afford the security that is wanted, except the legislature?"(John Stuart Mill, "Employment of Children in Manufactories", The Examiner, 29 January 1832, p.67)

\section{Introduction}

According to ILO statistics (see ILO [12]), in 1995 at least 120 millions of children between five and twelve years of age worked full time in paid jobs, mostly in underdeveloped regions. This impressive figure awakes concern both in developing and developed countries and commands theoretical as well as policy-oriented analysis.

Historically, the most important and common intervention against child labor has been the adoption of legislation, through compulsory schooling and child labor laws. However, the welfare implications of such legislation are highly debated and no unanimous opinion has been reached on this issue. Moreover, even if we accepted that mandatory measures are desirable from a social welfare point of view, a fundamental problem related to the enforcement of legislation banning child labor or regulating school attendance exists.

On the one hand, from an historical perspective, the effect of compulsory schooling legislation (CSL) on child labor and school attendance is still an open question. Recent econometric works on the U.S. experience in the XX century reach inconclusive results. While Angrist and Krueger [1] and Margo and Finegan [17] conclude that CSL effectively raised educational attainment, Moehling [18] finds that CSL had little effect on the long run decline in child labor. As Basu [3] puts it in his excellent survey of the literature on the economics of child labor, "what Moehling study points to is the inadequate implementation of US law. This does not mean that the law is not the right method of intervention for eradicating child labor. Another country at another point in history may be able to implement a law that had, allegedly, failed elsewhere in the late nineteenth century" (Basu [3], p.1091). This view is consistent with the opinion of many economic historians that the little impact of CSL on child attendance in the late nineteenth century was due to the difficulty in enacting and enforcing the legislation (see, for example, Landes and Solmon [14]).

On the other hand, statistics on national education systems, school enrollment rates and child labor incidence reveal some interesting facts. First, according to UNESCO statistics [23], most developing countries have long since introduced legislations which, in 
terms of duration, are comparable with those in force in developed countries and include secondary-level education within compulsory education. ${ }^{1}$ Exceptions are mostly found in Sub-Saharan Africa (but also in Central America, the Antilles, the Arab States and South Asia) where compulsory education covers only primary education in some cases. Second, while the average gross enrolment rate at the primary level was around $100 \%$ in 1995 both in developed and developing countries (with the exception of African and Arab countries were it was around $80 \%$ ), the average school enrollment rate at the secondary level was around 50\% in most developing regions (as compared to $99.5 \%$ in developed countries), ranging from a maximum of $60 \%$ in East Asia and Oceania to a minimum of $25 \%$ in Sub-Saharan Africa. Finally, ILO estimates [11] show that average participation rates (full-time work) for children of age 10-14 were above $10 \%$ in most developing regions in 1995, with a peak in Sub-Saharan Africa where such rate was around $25 \%$.

Both historical facts and international statistics seem to show that a careful analysis of child labor must take into account observed cross-country differences in terms of response to legislation and investigate the conditions that determine whether or not legislation is effectual. In fact, it is widely recognized that the lack of enforcement mechanisms is a major obstacle to eliminate child labor (see, for example, Grootaert and Kanbur [10]). Enforcement problems are particularly severe in the informal sector, away from cities and in agriculture, in domestic service and home-based work. Since most children work in these sectors, most of them work where legislation on education and child labor can be virtually absent. Other reasons for the weakness of enforcement mechanisms against child labor include the lack of transportation which makes it very difficult to monitor establishments in rural areas, complexity and gaps in the law, inadequacy of penalties and uncertainty about the competent authority.

This paper contributes to the debate about child labor and legislative measures against it. More specifically, we consider school attendance as the major alternative to work ${ }^{2}$ and focus our attention on the importance of institutions which determine the actual enforcement of CSL and on economic factors affecting the level of enforcement that has to be reached in order to successfully eradicate child labor.

\footnotetext{
${ }^{1}$ This implies that in most countries, children are required to attend school at least up to fourteen years of age.

${ }^{2}$ Some empirical studies on the relationship between education and child labor shows that these activities can be complementary, especially in rural areas and in the urban informal sector (see for example Patrinos and Psacharopoulos [19] and Grootaert [9]). However, many other studies corroborate the idea that fulltime work in the formal sector is detrimental for educational attainment (see, among others, Canagarajah and Coulombe [5], Jensen and Nielsen [13] and Psacharopoulos [20]).
} 
To analyze these issues, we model an economy with heterogenous agents where the rationale for public intervention through compulsory schooling legislation is the presence of complementarities in the production of human capital which affect the choice between education and child labor. In particular, we assume that, for each household, the net benefit of sending children to school rather than to work is increasing with the fraction of children who simultaneously attend school. This assumption can be interpreted in two ways. Either there exist positive externalities in education, so that the individual profitability of investment in education is higher the larger is the fraction of agents attending school, or social acceptance of child labor is lower the smaller is the fraction of children at work. ${ }^{3}$

Consistently with our previous discussion, we allow for the possibility that full enforcement of legislation on compulsory education cannot always be achieved. In particular, we assume that the ability to enforce the law depends on factors such as the level and quality of legal and physical infrastructure, the efficiency of the administrative system, the socio-political environment, etc., which we take as exogenous and call the "quality of institutions". In our model, the quality of institutions is represented by the probability of being caught breaking the law, which also represents the number of children who are forced by law to attend school. This is one of the key elements taken into account by agents who evaluate the expected utility of different courses of action.

Within this framework, we show that, even in the presence of CSL, child labor can emerge as the consequence of coordination failures such that some children are withdrawn from school by their parents who rationally expect that only a small fraction of the households will send children to school. ${ }^{4}$ These coordination failures arise when the quality of institutions and legislation enforcement is low relative to an endogenous threshold, which depends on preferences and technology parameters as well as on income distribution.

More specifically, when the quality of institutions is lower than the threshold, multiple equilibria arise so that child labor cannot be completely eradicated and will occur more often among the poorest segment of the population. In the opposite case where institutions ensure that at least a critical fraction of children attends school, a unique equilibrium exists such that it is profitable for all households to follow compulsory schooling laws and send their children to school.

The main implication of these results is two-fold. First, similar countries that differ

\footnotetext{
${ }^{3}$ In what follows, we emphasize the former point of view, but it is possible to interpret all our results in terms of the latter.

${ }^{4}$ For the analysis of coordination failures in macroeconomics, see Cooper [6].
} 
only with respect to the quality of institutions and the degree of enforcement may reach equilibria characterized by very different levels of child labor incidence. Second, countries with similar levels of aggregate income and quality of institutions may experience very different levels of child labor whenever differences in preferences, technology and income distribution give rise to different thresholds and therefore would require different qualities of institutions in order to fully eliminate child labor.

We then turn to the investigation of the welfare implications of the introduction of CSL. Despite the existence of coordination failures in human capital accumulation quite naturally calls for legislations making school attendance compulsory, our analysis shows that the effect of such interventions are not clear-cut. On the one hand, when the degree of enforcement is high, the adoption of CSL represents a welfare improvement, since it solves the coordination failure, eradicates child labor and increases the utility of all households. On the other hand, when the degree of enforcement is low, legislation does not eradicate child labor and, contrary to the wisdom of the typical policymaker, it certainly hurts the poor and a fraction of the middle class for whom the gain associated to increased average school attendance is not enough to compensate for the loss deriving from forced attendance.

This paper is related to a growing theoretical literature on the economics of child labor (see, for example, Baland and Robinson [2], Basu and Van [4], Lopez-Calva and Rivas [15], Ranjan [21] and Swinnerton and Rogers [22]). The contributions which are closest in spirit to ours are, however, Dessy [7] and Dessy and Pallage [8]. In Dessy and Pallage [8], child labor arises because of coordination failures between parental decisions to invest in their offspring education and firms' investment in skill-intensive technologies. The effect of legislative intervention is only briefly discussed and no attention whatsoever is paid to the imperfect enforcement of legislation. Dessy [7] analyzes the relationship between endogenous fertility, child labor and economic growth. Within this framework, he discusses the effects of compulsive measures against child labor, and concludes that compulsory education is always desirable (even if partially enforced) since it decreases the threshold level of initial human capital which is necessary to reach the steady-state with high growth and no child labor.

The rest of the paper is organized as follows. Section 2 sets out the model. In Section 3 we introduce our definition of equilibrium, show the conditions under which multiple equilibria emerge and characterize these equilibria. Section 4 develops the welfare analysis and Section 5 concludes. 


\section{The model}

Consider a two-period economy populated by a continuum of households composed by one parent and one child. Parents live for one period, children for two.

In the first period, children may either go to school or work (child labor). Labor income earned by children (normalized to one) is added to family income and used for family consumption. When adults, agents inelastically supply their unit of time in the labor market, earning an income proportional to their human capital:

$$
y=h
$$

where $h$ is the level of human capital. Human capital of parents is distributed according to some continuously differentiable cumulative probability distribution function $\Phi$. There is a positive density $\varphi(h)$ at all positive human capital levels $h \in[1, \bar{h}]$.

Adults are altruistic and trade off their children future income with current family consumption. The utility function of the adult is assumed to be linear:

$$
u\left(C, y_{2}\right)=C+\beta y_{2}
$$

where $C$ denotes consumption of household in the first period, $y_{2}$ is the income of the children in the second period and $\beta \in(0,1)$ denotes the degree of altruism. Household consumption is equal to household income which is the sum of the income of the adult and the income of the child if she does not attend school.

The only economic decision taken by agents is for parents to choose whether to send their children to school or work. Technology for human capital production is such that the return to individual investment in education is positively related to parental human capital and to the fraction $n$ of children simultaneously attending school. In other words, we assume that there exist positive externalities in education both at the household and at the aggregate level. However, as the following analysis makes clear, only the latter assumption is strictly necessary for our results. ${ }^{5}$ In particular, if we denote with $h_{2}$ the level of human capital of children in the second period, we have:

$$
h_{2}=g(h) f(n)
$$

where we assume that $g(0)=0, g(1)>1, g^{\prime}(h)>0, g^{\prime \prime}(h)<0, f(0)=1, f^{\prime}(n)>0$ and $f^{\prime \prime}(n)<0$.

\footnotetext{
${ }^{5}$ As discussed above, the former assumption has been introduced to accomodate our analysis to the stylized fact that the rich seldom send children to work.
} 
Compulsory schooling legislation requires that all children attend school in order to fully exploit human capital externalities. However, the enforcement of legislation depends on plenty of factors, such as the level and quality of legal and physical infrastructure, the efficiency of the administrative system, socio-political environment, which we define as the "quality of institutions".

In particular, we assume that the higher the quality of institutions, the higher is the probability $p$ that an infraction of the law (i.e. sending children to work) is detected. Parents who are caught breaking the law are forced to send their children to school. By the law of large numbers, $p$ therefore represents also the fraction of children that are forced to attend school. We assume that the return to individual investment in education is lower in this case than in the case where parents voluntarily send children to school. Formally, we assume that:

$$
h_{2}=\left\{\begin{array}{l}
g_{H}(h) f(n) \text { if attendance is voluntary } \\
g_{L}(h) f(n) \text { if attendance is forced }
\end{array}\right.
$$

where $g_{H}(h)>g_{L}(h)>1$ for every $h^{6}$

\section{The equilibrium}

In the first period, adults must choose whether to send their children to school or to work by comparing the levels of utility they can expect to obtain in the two alternative cases. As we discussed above, if the child goes to school at time 1, her income at time 2 depends on the number of children who go to school at time 1. Thus, when making their economic decision, adults must form an expectation about how many children will end up attending school in that period.

If the child attends school, household expected utility is equal to:

$$
y+\beta g_{H}(h) f(\widetilde{n})
$$

where $\widetilde{n}$ is the expected share of children attending school.

If the child goes to work, household expected utility is given by:

$$
y+(1-p)+\beta\left[p g_{L}(h) f(\widetilde{n})+(1-p)\right]
$$

Given the above discussion, we are ready to state our definition of equilibrium:

\footnotetext{
${ }^{6}$ This assumption can be justified assuming that some time elapses before working children who are identified by the authorities and redirected to schools succesfully adjust to the new environment.
} 
Definition A self-fulfilling equilibrium is a set of couples $(e, \widetilde{n})$ for each household such that:

(i) given $\widetilde{n}, e \in\{0,1\}$ solves the individual maximization problem:

$$
\max _{e \in\{0,1\}}\left\{y+(1-e)(1-p)+e \beta g_{H}(h) f(\widetilde{n})+(1-e) \beta\left[p g_{L}(h) f(\widetilde{n})+(1-p)\right]\right\}
$$

(ii) $\widetilde{n}=n$ for all households.

In words, the equilibrium is such that each household sends her children to school (that is, $e=1$ ) if and only if it is rational to do so given their own expectation about how many other children will be sent to school. Moreover, each household expectation is correct. In order to characterize the equilibrium, we can now prove the following important result:

Proposition 1 There exists a $p^{*} \in[0,1)$, where $p^{*}$ is the unique solution to:

$$
g_{H}(\bar{h})-p g_{L}(\bar{h})=[(1+\beta)(1-p)] / \beta f(p)
$$

such that, if $p \geq p^{*}$, the only self-fulfilling equilibrium is $(1,1)$ for each household.

Proof. Notice that by definition $p^{*}$ represents the minimum quality of institutions which ensures that the richest families certainly send their children to school. Two cases arise. If $g_{H}(\bar{h}) \geq(1+\beta) / \beta$, then $p^{*}=0$. If $g_{H}(\bar{h})<(1+\beta) / \beta, p^{*} \in(0,1)$ as an inspection of equation (8) easily shows. Both sides are strictly decreasing with $p$. On the one hand, when $p \rightarrow 0$, the left-hand side of the above equation is smaller than the right-hand side. On the other hand, when $p \rightarrow 1$, the left-hand side is larger than the right-hand side. Thus, the two sides of equation (8) must be equal for a unique level of $p \in(0,1)$. Since human capital is continuously distributed and the richest $p l u s$ a share $p^{*}$ of the population certainly attend school, also the next richest families find it profitable to send their children to school, and so on until everybody attends school.

As the above proposition shows, if the quality of institutions is sufficiently high, that is if $p \geq p^{*}$, the existence of CSL solves the coordination failure problem and ensures that the only possible equilibrium is one where child labor is completely eradicated. Since a critical mass $p^{*}$ of households is known with certainty to attend school, it is profitable for the richest to voluntarily withdraw children from work. Knowing this, the next to richest families also find it profitable to withdraw children from work and this virtuous process trickles down layer by layer to the poorest.

It is important to notice that the threshold level $p^{*}$ that must be achieved in order for the trickle down process to start is endogenous and depends on various factors. First, the 
characteristics of income distribution play a relevant role in determining the effectiveness of legislation. Observation of equation (8) shows that $p^{*}$ is decreasing with ceteris paribus increases of the income of the richest. This result can be interpreted as follows. Take two countries with the same preference, technological parameters and quality of institutions but different income distributions. In particular, let us assume that they have the same average income even though in the first one the income of the richest is higher than in the second one. Equation (8) shows that the first economy will have a lower threshold $p^{*}$ and therefore will be more likely to end up in the equilibrium where every parents send their children to school. ${ }^{7}$

Second, it is immediate to verify that $p^{*}$ is decreasing with ceteris paribus changes in parameters that increase the relative profitability of voluntary school attendance and/or decrease the profitability of forced school attendance for the richest, that is with upward shifts of $g_{H}(\bar{h})$ and/or downward shifts of $g_{L}(\bar{h})$. In particular, when the profitability of investment in education for the richest is sufficiently high, that is $g_{H}(\bar{h}) \geq(1+\beta) / \beta, p^{*}$ becomes arbitrarily small and the quality of institution becomes irrelevant. Finally, when $\beta$ increases and parents become more altruistic, the threshold level $p^{*}$ decreases.

Let us now analyze the case where $0<p<p^{*}$, that is $g_{H}(\bar{h})<(1+\beta) / \beta$. We can show the following preliminary result:

Proposition 2 Let $(C 1): g_{H}(1)-p g_{L}(1)>[(1+\beta)(1-p)] / \beta f(1)$ (that is, the poorest gain from investing in education when everybody else invests) and $(C 2): g_{H}^{\prime}(h)-p g_{L}^{\prime}(h)>0$ hold. Then, there exists a unique human capital level $h^{*} \in(1, \bar{h})$ such that all families with $h<h^{*}$ send their children to work and those with $h>h^{*}$ send their children to school. The level of human capital $h^{*}$ is the unique solution to the equation:

$$
g_{H}(h)-p g_{L}(h)=[(1+\beta)(1-p)] / \beta f(\widetilde{n})
$$

where

$$
\widetilde{n}=[1-\Phi(h)]+p \Phi(h)
$$

Moreover, $\partial h^{*} / \partial p<0$.

Proof. Notice that the right-hand side of the equation which defines $h^{*}$ (after substituting for $\widetilde{n})$ is increasing with $h$ between $[(1+\beta)(1-p)] / \beta f(1)$ and $[(1+\beta)(1-p)] / \beta f(p)$.

\footnotetext{
${ }^{7}$ In fact, if $h$ were discretely distributed, the relevance of distributional factors would be even stronger, since the relative size of income classes as well as the relative distance between income classes would obviously affect $p^{*}$.
} 
By assumption, the left-hand side is strictly increasing with $h$ and its maximum is lower than the maximum of the right-hand side. Finally it is immediate to verify that by assumption, the minimum of the left-hand side is larger than the minimum of the right-hand side. The sign of the derivative of $h^{*}$ with respect to $p$ is easily determined by applying the implicit function theorem.

In words, if the poorest agents benefit from investment in their offsprings education when everybody else invests (condition $(C 1))^{8}$, and the richest do not benefit from investing when nobody voluntarily invests $\left(p<p^{*}\right)$, then there exists a threshold level of individual human capital $h^{*}$ which separates those who voluntarily send their children to school from those who do not.

Notice that if condition $(C 2)$ does not hold, only agents with human capital below $h^{*}$ would send their children to school. Since this would contradict the empirical observation that poverty is a major explanation for child labor, we henceforth assume that condition $(C 2)$ is satisfied.

As the next result will prove, the same condition which guarantees the existence of the threshold level $h^{*}$ implies that multiple equilibria exist. More specifically, we have:

Proposition 3 For any $p \in\left[0, p^{*}\right)$, there exists a self-fulfilling equilibrium such that $e=$ 0 and $\widetilde{n}=p$ for all households. If and only if $(C 1)$ is satisfied, two more self-fulfilling equilibria exist. The former is such that $e=1$ and $\widetilde{n}=1$ for all households. The latter is such that $e=1$ for $h>h^{*}, e=0$ for $h<h^{*}$ and $\widetilde{n}=\left[1-\Phi\left(h^{*}\right)\right]+p \Phi\left(h^{*}\right)$.

Proof. Since $p<p^{*}$ and therefore $g_{H}(\bar{h})-p g_{L}(\bar{h})<[(1+\beta)(1-p)] / \beta f(p)$, the equilibrium where everybody expect that nobody will voluntarily send children to school is self-fulfilling. Next, note that a self-fulfilling equilibrium with no child labor requires that the poorest send children to school under the expectation of full attendance, that is $(C 1)$ must be satisfied. Finally, the fact that $(C 1)$ and $(C 2)$ hold ensures that there also exists $h^{*} \in(1, \bar{h})$ such that the expectation that only children belonging to rich families and those who are forced by law attend school is self-fulfilled.

The above result shows that, when the quality of institutions is lower than the threshold that would ensure full effectiveness of legislation, child labor can emerge, even in the presence of compulsory education laws. This possibility is the consequence of coordination failures such that (some fraction of the) children are withdrawn from school by their

\footnotetext{
${ }^{8}$ Notice that a sufficient condition for $(C 1)$ to hold is $\beta g_{L}(1) f(1)>1+\beta$.
} 
parents who rationally expect that only a small fraction of the households will send children to school. If condition $(C 1)$ does not hold, and the poorest agents never find profitable to send their children to school, the only possible self-fulfilling equilibrium is such that no one voluntarily attends school. ${ }^{9}$

\section{Welfare analysis}

The three equilibria that we characterized in the previous section can be ranked in terms of welfare. In particular, it can be easily noticed that each household prefers the equilibrium where everybody invests in education (the "good" equilibrium) to the equilibrium where only household with human capital above $h^{*}$ invest (the "intermediate" equilibrium). In turn, the latter equilibrium is unanimously preferred to the equilibrium where everybody sends children to work (the "bad" equilibrium).

In what follows, we use these results to analyze the welfare implications of the introduction of CSL. Obviously, the case where no legislation exists is equivalent to the case where $p=0$. Therefore, given $p$, in order to determine whether or not CSL is welfareimproving, we must compare the level of expected welfare achieved when the quality of institutions is equal to $p$ with the level achieved when $p=0$.

If the quality of institutions is such that at least a fraction $p^{*}$ of children can be forced to attend school, then the adoption of CSL eradicates child labor, ensures that each household achieves the highest level of utility and maximizes aggregate expected welfare by eliminating the possibility of inefficient equilibria.

What is the welfare effect of CSL when the quality of institutions is lower than $p^{*}$ ? On the one hand, if condition $(C 1)$ does not hold, nobody voluntarily sends children to school and CSL hurts all agents by introducing the possibility of being forced to attend school.

On the other hand, if condition $(C 1)$ is satisfied, compulsory education does not solve the coordination failure and expectations determine the equilibrium outcome. In this case, we can prove the following result:

Proposition 4 Let $0<p<p^{*}$. Then, with the adoption of CSL, the expected utility of all agents decreases in the bad equilibrium. In the intermediate equilibrium, the expected utility of agents with human capital above (below) $\widehat{h}(p)$ increases (decreases), where $\widehat{h}(p) \in$

\footnotetext{
${ }^{9}$ Notice that if we assumed that the income of the poor is given by $\underline{h}$, condition $(C 1)$ would be less likely to be satisfied the lower is $\underline{h}$. In other words, when $p<p^{*}$, a lower income of poorest increases the likelihood of reaching the equilibrium with the highest level of child labor.
} 
$\left(h^{*}(p), h^{*}(0)\right)$ is defined by $\beta g_{H}(\widehat{h}(p)) f(\widetilde{n})=1+\beta$. In the good equilibrium, the expected utility of all agents is unchanged.

Proof. See Appendix A.

The above result can be given the following explanation. CSL has clear-cut effects on aggregate expected welfare if the economy ends up in one of the extreme equilibria. In particular, CSL has adverse effects if the economy ends up in the bad equilibrium, since agents who do not voluntarily invest achieve the highest level of expected utility if there is no chance to be caught, while it has no effects if the economy ends up in the good equilibrium, since everybody voluntarily invests in education in this case.

In the intermediate equilibrium, the introduction of CSL will certainly hurt agents with human capital below $h^{*}(p)$ who never invest in education and benefit agents with human capital above $h^{*}(0)$ who would invest anyway (since the profitability of their investment in education increases when a larger fraction of agents attends school). Agents with human capital between $h^{*}(p)$ and $h^{*}(0)$ find it optimal to invest in the presence of CSL but would not invest in its absence. The above results show that some of them (that is, those between $h^{*}(p)$ and $\widehat{h}(p)$ ) would rather not introduce CSL (and thus not invest), whereas the others (that is, those above $\widehat{h}(p)$ ) would rather introduce CSL (and thus invest).

More interestingly, a closer look at Proposition 4 reveals that we can derive general (in that they do not depend on the realized equilibrium) welfare implications for some class of agents. In particular, we can make the following remark:

Remark 5 If $p<p^{*}$, independently from the realized equilibrium, the institution of CSL implies that the expected utility of agents with human capital below $\widehat{h}(p)$ either decreases or is unchanged.

When the quality of institutions is not high enough to guarantee full school attendance, the adoption of CSL brings about redistributive implications that tend to hurt the poor and implies a welfare loss for agents with human capital below the threshold $\widehat{h}(p)$. Again, notice that the adoption of CSL results in a welfare loss not only for very poor agents, that is agents with human capital below $h^{*}(p)$, who always send children to work unless they expect full school attendance, but also for a fraction of the middle class, that is agents with human capital between $h^{*}(p)$ and $h^{*}(0)$, who invest in education given the presence of CSL but nevertheless would prefer that CSL had not been introduced in the first place.

The above remark shows that general welfare implications of the adoption of CSL can be derived for the poor without introducing assumptions on the likelihood of equilibria. 
To go further, and derive general welfare implications for the rich and the economy as a whole, one must necessarily attribute a probability to the realization of each equilibrium. Since such probabilities are completely exogenous in our set up when $p<p^{* 10}$, a rule of thumb way to proceed would attribute equal probability to each equilibrium.

Let us now explore the effects of CSL on aggregate expected welfare under this assumption. Aggregate expected welfare as a function of $p$ can be written as:

$$
W(p)=\frac{1}{3}\left[W_{B}(p)+W_{I}(p)+W_{G}\right]
$$

where $W_{B}(p)$ denotes aggregate expected welfare in the bad equilibrium, $W_{I}(p)$ is the aggregate expected welfare in the intermediate equilibrium and $W_{G}$ is the constant welfare achieved in the good equilibrium. Assuming that the aggregate welfare function puts equal weight on each household, we have:

$$
\begin{gathered}
W_{B}(p)=(1+\beta)(1-p)+\beta p f(p) \int_{1}^{\bar{h}} g_{L}(h) \varphi(h) d h \\
W_{I}(p)=(1+\beta)(1-p) \Phi\left(h^{*}\right)+\beta p f(\widetilde{n}) \int_{1}^{h^{*}} g_{L}(h) \varphi(h) d h+ \\
+\beta f(\widetilde{n}) \int_{h^{*}}^{\bar{h}} g_{H}(h) \varphi(h) d h
\end{gathered}
$$

In the bad equilibrium, everybody sends children to work and aggregate expected welfare is the sum of the welfare of household who are caught and forced to send children to school and those who are not. In the intermediate equilibrium, aggregate expected welfare is the sum of the expected welfare of the poor who send children to work (given by the first two terms in equation (12)) and the welfare of the rich who voluntarily send children to school (given by the third term in equation (12)).

As we know from Proposition 4, the introduction of CSL brings about redistributive implications that hurt the poor and possibly benefit the rich, when $p<p^{*}$. Therefore, it is reasonable to expect that there will exist cases where the introduction of CSL reduces aggregate expected welfare. The following result shows that this is indeed the case when the quality of institutions is very low:

Proposition 6 Let $f^{\prime}(0)<\infty$. Then $\lim _{p \rightarrow 0} \frac{\partial W}{\partial p}<0$.

Proof. The limit of $\frac{\partial W}{\partial p}$ when $p \rightarrow 0$ is given by:

\footnotetext{
${ }^{10}$ Obviously, when $p>p^{*}$, the good equilibrium is realized with probability one.
} 


$$
-(1+\beta)\left[1+\Phi\left(h^{*}(0)\right)\right]+\beta\left\{\int_{1}^{\bar{h}} g_{L}(h) \varphi(h) d h+f\left[1-\Phi\left(h^{*}(0)\right)\right] \int_{1}^{h^{*}(0)} g_{L}(h) \varphi(h) d h\right\}
$$

Notice that $(1+\beta)>\beta \int_{1}^{\bar{h}} g_{L}(h) \varphi(h) d h$. Furthermore, using equation (9), it is immediate to verify that $\beta f\left[1-\Phi\left(h^{*}(0)\right)\right] \int_{1}^{h^{*}(0)} g_{L}(h) \varphi(h) d h<(1+\beta) \Phi\left(h^{*}(0)\right)$.

The question remains open whether the latter conclusion can be reverted as the quality of institution increases, that is if $W(p)>W(0)$ for some $p<p^{*}$. This question cannot be unambiguously answered without introducing additional restrictions on technology and distribution.

\section{Conclusions}

In this paper, we analyzed how the (possibly imperfect) enforcement of compulsory schooling legislation affects the choice between child labor and education in a model where public intervention is justified by the presence of coordination failures in the process of human capital accumulation. Our work provides theoretical support to the idea that the effects of legislative measures against child labor cannot be seriously discussed without taking into account the key issue of enforceability, since most developing countries do not have the administrative capacity to fully enact child labor and compulsory schooling laws.

We showed that if legislation is sufficiently (even if not completely) enforced, compulsory schooling laws ensure that a unique equilibrium exists where coordination failures are solved and all parents send their children to school. In this case, legislation allows to reach the social optimum.

On the contrary, if enforcement is low, coordination failures cannot be solved and multiple equilibria may emerge. In this case, child labor can be the equilibrium outcome and compulsory schooling legislation can have adverse effects on aggregate welfare. Contrary to some theoretical contributions (see for example Dessy ([7])) and the wisdom of the typical policymaker, we showed that the adoption of legislation has unambiguous negative effects on the poor and a fraction of the middle class.

Since the minimum degree of enforcement that allows to successfully eradicate child labor depends on technology and preference parameters as well as on income distribution, countries with similar levels of aggregate income and quality of institutions may respond very differently to the introduction of compulsory schooling legislation. 


\section{References}

[1] Angrist, J. D. and A. B. Krueger (1991), "Does Compulsory School Attendance Affect Schooling and Earnings", Quarterly Journal of Economics, 106, 979-1014.

[2] Baland, J-M. and J. A. Robinson (2000), "Is Child Labor Inefficient?", Journal of Political Economy, 108(4), 663-679.

[3] Basu, K. (1999), "Child Labor: Causes, Consequence, and Cure, with Remarks on International Labor Standards", Journal of Economic Literature, 37, 1083-1119.

[4] Basu, K. and P. H. Van (1998), "The Economics of Child Labor", American Economic Review, 88(3), 412-427.

[5] Canagarajah, R. and H. Coulombe (1997), "Child Labor and Schooling in Ghana", Human Development Tech. Report (Africa Region), World Bank.

[6] Cooper, R. W. (1999), "Coordination Games: Complementarities and Macroeconomics", Cambridge University Press.

[7] Dessy, S. E. (2000), "A Defense of Compulsory Measures Against Child Labor", Journal of Development Economics, 62, 261-275.

[8] Dessy, S. and S. Pallage (2000), "Child Labor and Coordination Failures", Working Paper no. 109, University of Quebec.

[9] Grootaert, C. (1999), "Child Labor in Cote d'Ivoire: Incidence and Determinants", in The Policy Analysis of Child Labor: A Comparative Study, C. Grootaert and H. Patrinos eds., MacMillan.

[10] Grootaert, C. and R. Kanbur (1995), "Child Labor: A Review", Policy Research Working Paper 1505, The World Bank.

[11] ILO, (1996), "Economically Active Populations: Estimates and Projections", 19502010, Geneva.

[12] ILO (1998), "Report VI (1): Child Labour: Targeting the intolerable", Geneva.

[13] Jensen, P. and H.S. Nielsen (1997), "Child Labor or School Attendance? Evidence from Zambia", Journal of Population Economics, 10, 407-424. 
[14] Landes, W. and L. Solmon (1972), "Compulsory Schooling Legislation: An Economic Analysis of Law and Social Change in the Nineteenth Century", Journal of Economic History, 32(1), 54-91.

[15] Lopez-Calva, L. F. and L.A. Rivas (2000), "Capital Accumulation and Child Labor: Can Compulsory Schooling Be Counterproductive?", mimeo.

[16] Mill, J.S. (1832), "Employment of Children in Manufactories", The Examiner, January.

[17] Margo, R. A. and T. A. Finegan (1996), "Compulsory Schooling Legislation and School Attendance in Turn-of-the Century America: A natural experiment approach", Economics Letters, 53, 103-110.

[18] Moehling, C. M. (1999), "State Child Labor Laws and the Decline of Child Labor", Explorations in Economic History, 36(1), 72-106.

[19] Patrinos, H. A. and G. Psacharopoulos (1997), "Family Size, Schooling and Child Labor in Peru", Journal of Population Economics, 10(4), 387-405.

[20] Psacharopoulos, G. (1997), "Child Labor versus Educational Attainment: Some Evidence from Latin America", Journal of Population Economics, 10(4), 377-386.

[21] Ranjan, P. (1999), "An Economic Analysis of Child Labor", Economics Letters, 64, 99-105.

[22] Swinnerton, K. A. and C. A. Rogers (1999), "The Economics of Child Labor: Comment", American Economic Review, 89(5), 1382-1385.

[23] UNESCO Institute for Statistics, (1999), "UNESCO Annual Statistical Yearbook". 


\section{A Proof of Proposition 4}

First, consider the bad equilibrium. Let us show that for all $h,(1+\beta)>\beta g_{L}(h) f(p)$ so that $U_{B}(h, p)<U_{B}(h, 0)$ where $U_{B}(h, p)=(1+\beta)(1-p)+\beta p f(p) g_{L}(h)$ is the expected level of utility obtained by agent $h$ in the bad equilibrium when the quality of institutions is $p$ and $U_{B}(h, 0)$ is the expected level of utility obtained by agent $h$ in the bad equilibrium when there is no CSL. Suppose not. Since in the bad equilibrium nobody invests, it must be true that $\beta g_{H}(h) f(p)<(1+\beta)(1-p)+p \beta g_{L}(h) f(p)$. This would imply $\beta g_{H}(h) f(p)<$ $\beta g_{L}(h) f(p)$ which is a contradiction.

Second, consider the intermediate equilibrium. Agents with human capital below $h^{*}(p)$ never send children to school voluntarily and their expected utility is maximum when the probability of being caught is zero, that is when $p=0$. In fact, since $\beta g_{H}(h) f(\widetilde{n})<$ $(1+\beta)(1-p)+p \beta g_{L}(h) f(\widetilde{n})$, we have that $(1+\beta)>\beta g_{H}(h) f(\widetilde{n})>\beta g_{L}(h) f(\widetilde{n})$ and $U_{I}(h, p)<U_{I}(h, 0)$ for $h<h^{*}(p)$ where $U_{I}(h, p)=(1-p)(1+\beta)+p \beta g_{L}(h) f(\widetilde{n})$ is the expected level of utility obtained by agent $h<h^{*}(p)$ when the quality of institutions is $p$ and $U_{I}(h, 0)$ is the expected level of utility obtained by agent $h<h^{*}(p)$ when there is no CSL. For $h=h^{*}(p), \beta g_{H}\left(h^{*}(p)\right) f(\widetilde{n})=(1+\beta)(1-p)+p \beta g_{L}\left(h^{*}(p)\right) f(\widetilde{n})$. By continuity, $1+\beta \geq \beta g_{H}\left(h^{*}(p)\right) f(\widetilde{n})$. However, $\beta g_{H}\left(h^{*}(p)\right) f(\widetilde{n})=1+\beta$ would imply $g_{H}\left(h^{*}(p)\right)=$ $g_{L}\left(h^{*}(p)\right)$ which is a contradiction. Thus, $1+\beta>\beta g_{H}\left(h^{*}(p)\right) f(\widetilde{n})$. Agents with $h \geq h^{*}(0)$ always send children to school and their expected utility $U_{I}(h, p)=\beta f(\widetilde{n}) g_{H}(h) \geq 1+\beta$ increases with $p$, since more and more agents attend school in equilibrium. By continuity of $g_{H}(h)$, there must exist $\widehat{h}(p) \in\left(h^{*}(p), h^{*}(0)\right)$ such that $\beta g_{H}(\widehat{h}(p)) f(\widetilde{n})=1+\beta$. Thus, the introduction of $C S L$ implies that agents with $h \in\left(h^{*}(p), \widehat{h}(p)\right)$ are hurt since for them $\beta g_{H}(\widehat{h}(p)) f(\widetilde{n})<1+\beta$ where $1+\beta$ is their level of utility without $C S L$. Agents with $h \in$ $\left(\widehat{h}(p), h^{*}(0)\right)$ benefit from the introduction of $C S L$ since for them $\beta g_{H}(\widehat{h}(p)) f(\widetilde{n})>1+\beta$.

Third, consider the good equilibrium. Since in this case everybody voluntarily invest, the existence of CSL is completely irrelevant. 